\title{
Evaluating and monitoring of changes in the environmental elements by using remote sensing techniques in Iraq
}

\author{
Hussein Al-Tameemi ${ }^{1, *}$ \\ ${ }^{1}$ School of Engineering and Informatics, Sussex University, UK
}

\begin{abstract}
The primary aim of project highlight was to E\&M a universally-applicable suite of elements and techniques that allow remote sensing techniques to the E\&M-environmental changes and human interventions and the impact of disaster management systems for the period (2010-2015). The framework allows evaluators to monitor changes in a manner that is rapid, independent and reliable. Such a pattern is required to promote contribution and transparency towards a more systematic understanding of the process of E\&M. The factors are based on the use of Very High-Resolution Optical Satellite Imagery and have been developed to fit existing change approaches, such as the In-Disaster Needs Assessment-IDNA, and the Affected Cluster Framework. The elements encompass a range of environmental, climate, economic, health, physical and social factors, which can be analysed to provide a holistic representation of the E\&M changes process. The paper begins by addressing the need for a E\&M framework and by reviewing current guidelines and systems. Which are continuously developed in this case study. Recommendations are made on: 1- How to use disaster management systems; 2- Which elements should be monitored; and 3- How they can be evaluated, drawing on the experience of environmental scientific researcher, and feedback by the evaluators' academics.
\end{abstract}

\section{Introduction}

Main issues contributing to changing the outlook to bring the situation to an acceptable level to the evolution in the environment. The impact of the change is often long, and complex, with patterns and factors affected among numerous life sectors and its elements. There is a difference over time and the area of influence due to several factors, including socio-economic factors, and health-environmental, because of the multiplicity of decisions taken at the stage of change and after, which adversely affected it. There are subsequently similarities between change and environmental vulnerability theories, indicating that. There are weak factors, which in themselves are more likely to suffer serious losses, unable to recover with difficulty in the near or distant future as local environmental conditions. Post-disaster change is often conceptualised as a complex, multidimensional process. Often we find a reference to the period of the disaster [1].

The primary objective of these elements is often to differentiate emergency impact patterns from long-term change and mitigation. While the effect phase is characterised by changing of natural life tasks, such as high temperature is the first to cause desertification and drought, water scarcity and pollution; impact change is likely to include the climate environment (factors, values and patterns) and contribute to changing natural conditions to abnormal (water, soil thus the plant levels).
Hence, this article highlights the importance of the economic side and the ideological side according to the principles of change, as follows:

A. Environmental changes region: $78 \%$ of Iraq is assessed;

B. This region provides more than half of Iraq's production;

C. It is estimated that about $53 \%$ of the human population lives in this region;

D. One-third of Iraq's cities have a combined population of more than 32 million. Approximately $90 \%$ of the livelihoods of these people has been destroyed, region shown in Figure (1). Evaluating and monitoring the regions suffering change identifies: desertification, disaster-management systems impacts, and environmental pollution levels.

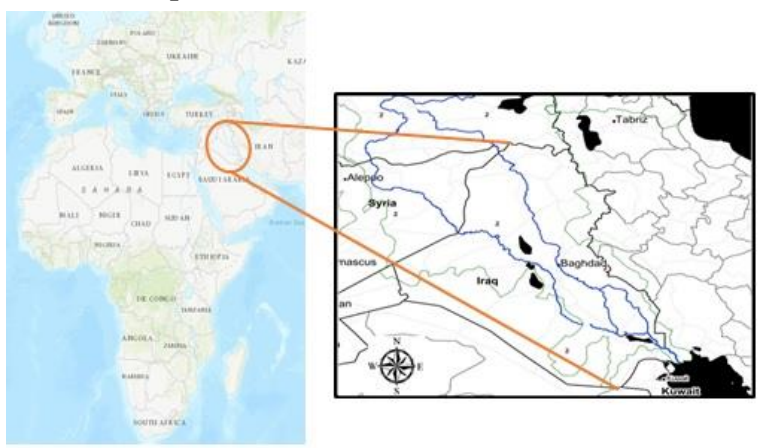

Fig .1. Study area of Iraq. 
The average impact of radioactive materials is estimated in Iraq's eastern, west, and southern environmental area. The trend of the higher-temperature system (HTS) for MODIS of Iraq [2, 9]. Environmental changes over time and space through sedimentation, and erosion during this dangerous phase of the Tigris-Euphrates Rivers for more than 25 years (1990-2017) is analysed and, shown in Figure (2). The analysis is based on the assessment of environmental-climatic changes in the central and southern cities. Studies conducted on the Shatt al-Arab estuary make comparisons of satellite imagery using MATLAB software. The environmental changes in Basra city, from 2001 to 2016 were estimated [7, 9, 17].

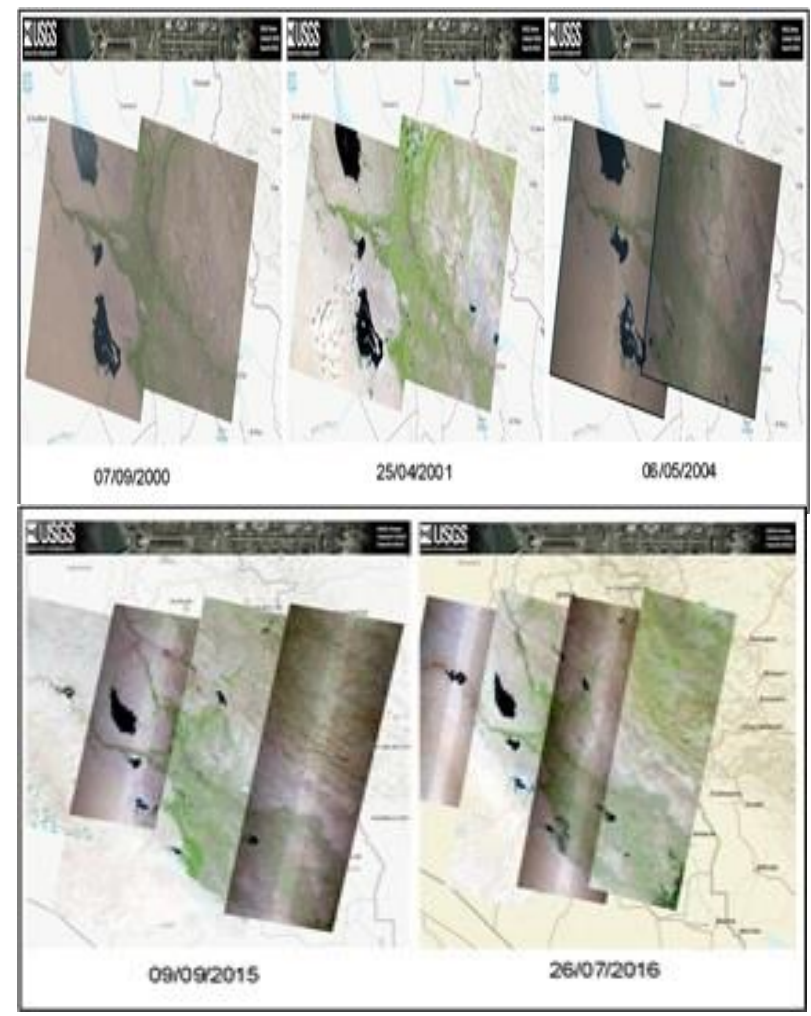

Fig.2. Environmental changes shown using satellite images of Iraq.

\subsection{Methods for E\&M of the environmental impact}

Iraq's fields are complex and with an ever-changing environment. Remote sensing is therefore important because of its great potential to provide an enormous amount of accurate and rigorous information, for planning and disaster management of Iraq's region. The evaluation of environmental changes with climate, and the analysis of data using the GIS technique establishes priorities $[3,4,1]$. Such, evaluation and monitoring are necessary to improve future aid policy to mitigate environmental impact, to provide time and to assist evaluators' with on-going work on the ground. Although many such research studies have been conducted in the past, with somewhat different ideas action paths: the priority now is to identify issues as they arise to inform decision-making and utilise analytical evaluations to guide environmental disasters management systems to mitigate the effects of climatic changes in Iraq. The evaluators try to assess the damages they are doing with their baseline changes [8]. They require data to provide the analytical basis for their decisions and to ensure that their objectives are being met on time. Much of the work is often pledged to assist people after massive natural disasters. Despite the fact that there is a large effort supporting work to aid E\&M, there are currently no standard frameworks or methodologies being applied, it is nevertheless possible to evaluate and monitor the process of change. In 1992, in June, a United Nations Conference on Environment \& Development was held in Rio de Janeiro-Brazil, where a discussion was held [17], which identified an urgent need for basic and applied research in the long-term evaluation processes for the years to come. In particular, the absence of a fixed and independent standard was observed to replicate the approach of using remote sensing techniques to monitor and assess the magnitude of impact and changes occurring in Iraqi environment. Figure (3) shows the changes of the environmental elements via temporal coverage from the Landsat 7 and $8 \mathrm{~L}-\mathrm{Sa}$-images between 1990-2015 in Iraq [16, 6, 5, 2]. More recently, the Active Environmental Assessment and Monitoring Techniques Association called for "The primary research is in the field of demonstrating the methods of assessment and the development of the most suitable solution for emergency response to disasters and risks".

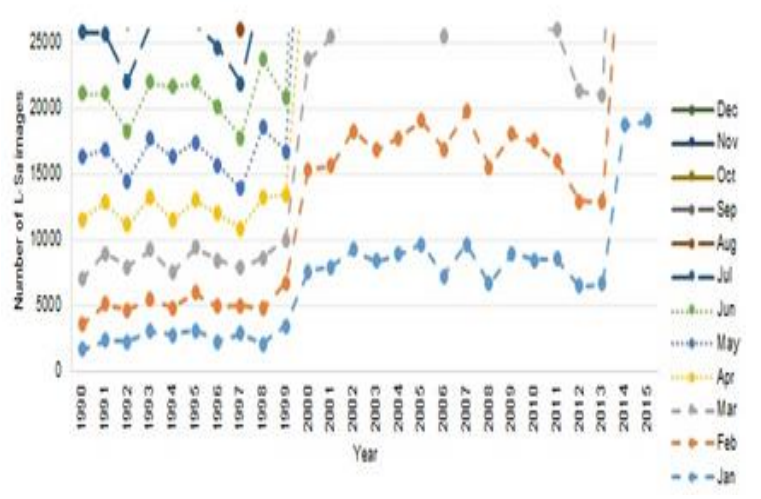

Fig.3. Changes to the environmental elements in temporal coverage of the Landsat 7 and 8 L-SA for 1990-2015 of Iraq.

\subsection{Methodology and analytical concept}

The main objective of the E\&M changes was to develop a standard approach to monitoring post-disaster environmental factors that are affected by change and instability. This is achieved through the use of highresolution satellite image datasets and spatial analysis within a Geographical Information System (GIS). The E\&M was conducted from 2010 to 2015. Appropriate case study sites were selected, and datasets were acquired and integrated into a single database in the path changes evaluation and monitoring [12, 3, 7]. A standardised monitoring framework was then developed after evaluating affected data levels and relevant values. Appropriate analysis indicators and techniques were 
developed and applied to the case study sites in the affected areas. This is supported by verification of the results of the analysis in detail, the level of evaluation by using data collected with advanced ground survey techniques and technique-audit methods [14]. A detailed impact-effectiveness analysis was then conducted to identify the weaknesses before the strengths of each element, and to provide evaluations on impact spread and how they may be monitored via remote sensing techniques. A set of Guidelines has been produced to introduce this approach and to demonstrate remote sensing as an appropriate monitoring tool [12]. The following sections describe the methodology in more detail:

\subsubsection{Assessment of the regional-local scale environmental changes}

The evaluators reviewed current regional, local scales frameworks, conducted a usé needs assessment during the evaluation of the affected area. That work resulted in a list of points that encompassed evaluation and analysis for long-term development. The points of joint action will be mentioned later $[10,16]$. Results demonstrated that all points received medium-to-high levels of prioritisation suggesting there was a strong view and preference for a comprehensive new approach to monitor and evaluate all changes, but that the points of interest differed according to the nature of the region. Selected techniques helped to highlight these specialised areas of interest. That said "In fact, we lack new and up-to-date information on patterns of damage at this point, which in turn has spread of the impact on the foundations of life and infrastructure (Josef Leitmann-Disaster Management Coordinator-World Bank-Indonesia). So, it would be good to handle overlapping satellite images to counteract these changes and stop the widening of damage in areas" Anne-Cécile Vialle - UNEP, "We need maps of environmental damage, economic loss, health loss, industrial and environmental sites, increased sites of harmful waste, including chemical, toxic, debris of war." Overall, at the local level, increasingly data is using environmental changes evaluation, such as satellite image data, such as figure (4).

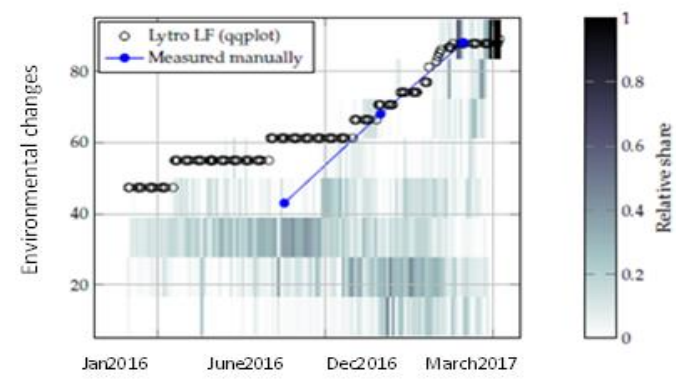

Fig.4. Iraq's environnemental changes.

Also, to reduce human intervention to minimise human impact on the lowest possible level and verify the high rate of assessment. It can briefly test by shortening work in two stages: (1) check for changing the numerical and colour values of a pixel at the satellite images during comparison with the previous image and map. (2) Making complete classifications of the pixel change scene, drawing on the principles and patterns of environmental change.

\section{Describe the analysis of environmental changes for GIS}

The VHR satellite imagery was analysed and techniques developed throughout the study period. A range of techniques was developed for each factor that uses both manual and semi-automatic procedures. The methods differ in the time and expertise required to conduct them including changes occurring now in the Iraq area. The remote sensing techniques and methods were first applied to the Al-Tameemi study and then applied to practical research by Al-Tameemi himself to test the transferability of the technical methodology. To summarise, the methodology is comprised of four components: 1. Technical processing 2. Database Creation 3. Data Analysis and 4. Establish full assessment of technology and process processing. Changes were monitored using a time-series of VHR satellite images acquired before the disaster, immediately afterwards and in the months-and-years after that in Iraq. While Maximum Likelihood Supervised Classification was used to create land cover maps marking out the extent of the built and natural environments changes. More advanced extraction techniques, such as Object-Based Image Analysis, were used to extract similar features of the impact and the environmental factors. These features were then integrated into a multi-temporal change Geodatabase as point GIS [13, 10, 11,15]. A new temporal layer of the database was derived from each satellite image, representing a different state in the process of impact changes. Each temporal layer was further divided into 12 thematic sub-layers, each representing one of the main performance factors $[15,17]$. Once the features in the imagery were mapped and stored in a GIS database of effect changes were determined by applying change detection analysis to the geodatabase. This technique calculates the rate that various processes were conducted, including temperature rise, salinity level, rivers pollution, desertification expansion compared to green vegetation, pollution areas as black spots, etc.

The method also identified when key features, such as population density, urbanisation, rural-to-urban areas migration $[10,3]$. The overall progress of E\&M changes was then factored by noting the presence or absence of the main features at different points in time. For more detailed analysis, the datasets were disaggregated by geographic boundaries, allowing disparity in the change levels to be assessed [11]. The progress of the effect was further evaluated by normalising the numbers of features (soil, water and vegetation) in each region to baseline statistical data of the satellite images, which were constructed using the pre-disaster image and the objectives of each evaluation- analysis project. This analysis was successful at identifying slow impacts and 
gaps in the environmental climate damages [15]. Overall, environmental changes and impact of damages were affected by variations in the performance of the economy, the social standard of the population, and unpredictable effects of nature.

This led to the conception of normative analytical systems organised in a detailed assessment on three crucial stages, as follows:

A) Environmental change levels, including evaluation, a high slope at temperature, a wetness index, soil salinity, desertification, lack of water levels and geomorphological types;

B) Water, including low rainfall, lack of river flow, and land migration;

C) Effect of socioeconomic levels, including population density, lack of resources, pollution, health deterioration rate, shown Figure (5). There is a direct and indirect impact on climate change with the environment, through a causal human lifestyle, and unstable development factors [12].

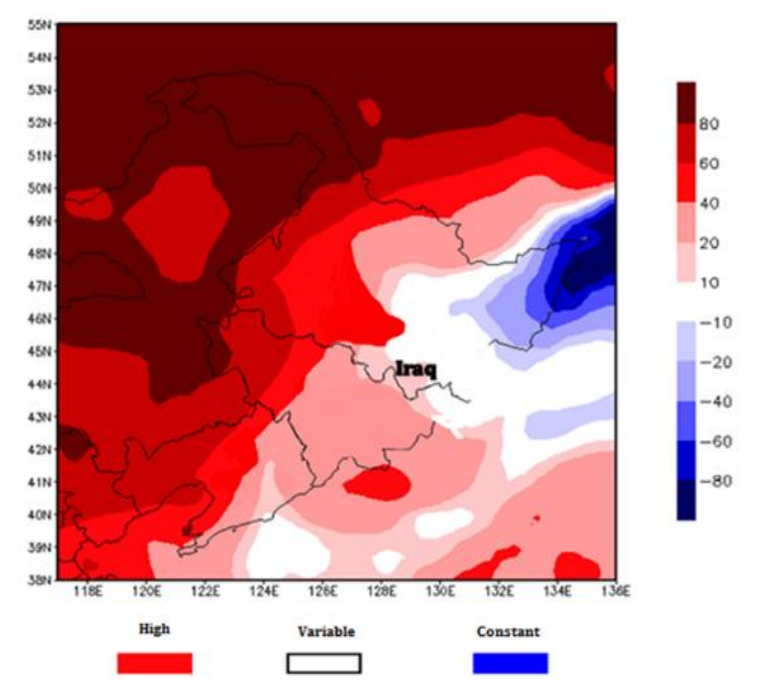

Fig. 5. Analytical-environnemental changes with GIS.

\section{Recycling environmental climate change data based on the remote sensing technique}

Balancing the rate of environmental changes causing in permanent differences, according to the selection and determination of the research area. Each region has significant damage that and changes the future life of the community. Additionally, environmental changes, ecological environment evaluations and crop yield assessment in the area. The available data has been used, such as temperature, remote sensing data and a worldclass scale of other data sets used [11].

\section{Results}

\subsection{Use of the statistics-analytical}

Each of the statistics provided a rich source of information that could be interpreted independently or integrated to provide a holistic understanding of the progress of evaluation. Analytical data evaluated, according to the principles of remote sensing was found to closely match statistics from key informants, focus group meetings and environmental changes $[9,17]$. Also, results were considered to be accurate when they were compared to detailed digital data collected using MATLAB. Moreover, the analysis also relied on many assumptions that weren't always accurate, such as, that all roads were in use and that all effects of damage change was found at the time the satellite images were acquired. These assumptions and errors were minimised in the environmental change knowledge data before the image analysis was begun by identifying likely forms of miss-interpretation and impact changes. In addition to the physical factor analysis, economic, social levels were successfully used to infer information about the evaluation and monitoring strategy $[16,11,10]$. A detailed discussion of these sectors and factors was not possible with remote sensing alone, but the information from satellite imagery was used to complement results acquired with ground surveys and modern techniques of the digital processing images with GIS [12]. Overall, a workflow of research was proposed that shows how the various instruments may be used in a complementary manner. GIS was found to be a suitable system in which to store and analyse the different datasets, including satellite imagery, ground-based observations and survey results data. The GIS also allowed multiple layers of the database to be examined simultaneously, thus providing a greater contextual understanding of the progress on the ground [8]. As an example of the results gained using this approach, a summary of the evaluation and monitoring process in the Al-Tameemi study after 2015 is presented in Table 1 shows a selection of the factors results from four months for 2011-2014.

\subsection{Case study: Al-Tameemi}

In Al-Tameemi, the 2010-2015 Iraqi environmental, climate change had a devastating effect on infrastructure and people's lives. Table 1 shows that over $45 \%$ of environmental factors were changed and nearly $35 \%$ of climate factors were impacted or in case of the continuous change in the Iraq areas. Also, figures (1-5) show how quickly disaster of change took place in the Al-Tameemi. In the Al-Tameemi study, natural resources were also affected by the changes, with severe damage to large tracts of land and urban green spaces. Livelihoods were disrupted by the impacts of the damage. All these activities were capable of being monitored with remote sensing. For example, image analysis showed an increase in the area effected by damage. This was validated with survey data from the Iraqi government and confirmed by UND and FAO reports between 2010-2015. The Tameemi study has not been completed to finish all changes in Iraq, which dates back to its beginnings in the year of 1990 . 
Table (1) Shows set of selecte results for the environnemental factor change of the Al-Tameemi study from four months for the period 2011-2014.

Table 1. The results for the environnemental factor.

\begin{tabular}{|c|c|c|c|c|}
\hline $\begin{array}{c}\text { Change } \\
\text { Indicator }\end{array}$ & $\begin{array}{c}\text { Pre- } \\
\text { Damage }\end{array}$ & $\begin{array}{c}\text { Post- } \\
\text { Damage }\end{array}$ & Jan2011 & Sep2014 \\
\hline $\begin{array}{c}\text { Damaged } \\
\text { Population }\end{array}$ & N/A & N/A & $4.5 \mathrm{M}$ & $2.6 \mathrm{M}$ \\
\hline $\begin{array}{c}\text { Total } \\
\text { Number of } \\
\text { Areas (City) }\end{array}$ & $14 / 18$ & $9 / 18$ & $16-13 / 18$ & $11-8 / 18$ \\
\hline $\begin{array}{c}\text { Effect } \\
\text { Temperatur } \\
\text { e }\end{array}$ & $10-39 \mathrm{C}^{0}$ & $22-58 \mathrm{C}^{0}$ & $18-24 \mathrm{C}^{0}$ & $46-60 \mathrm{C}^{0}$ \\
\hline $\begin{array}{c}\text { Rate } \\
\text { Salinity }\end{array}$ & $\begin{array}{c}1654 \mathrm{mg} \\
/ \mathrm{L}\end{array}$ & $\begin{array}{c}9875 \mathrm{mg} / \\
\mathrm{L}\end{array}$ & $\begin{array}{c}2623- \\
15416 \mathrm{mg} \\
/ \mathrm{L}\end{array}$ & $\begin{array}{c}85765- \\
126520 \mathrm{mg} \\
/ \mathrm{L}\end{array}$ \\
\hline $\begin{array}{c}\text { Quantity of } \\
\text { Groundwate } \\
\mathrm{r}\end{array}$ & 1.4 & $2.1 \mathrm{~m}^{3} / \mathrm{ye}$ & 1.9 & 3.1 \\
$\mathrm{~m}^{3} / \mathrm{year}$ & $\mathrm{ar}$ & $\mathrm{m}^{3} / \mathrm{year}$ & $1 \mathrm{year}$ \\
\hline $\begin{array}{c}\text { Rate } \\
\text { Desertificati } \\
\text { on }\end{array}$ & $36-48 \%$ & $70-92 \%$ & $68 \%$ & $93 \%$ \\
\hline $\begin{array}{c}\text { Rate } \\
\text { Pollution }\end{array}$ & $35-55 \%$ & $48-63 \%$ & $53 \%$ & $76 \%$ \\
\hline $\begin{array}{c}\text { Disease } \\
\text { Prevalence } \\
\text { Rate }\end{array}$ & $3.5-12 \%$ & $\begin{array}{c}10.6- \\
20 \%\end{array}$ & $9.76 \%$ & $17.99 \%$ \\
\hline \begin{tabular}{c} 
Effect Soil \\
\hline
\end{tabular} & $15-25 \%$ & $48-60 \%$ & $51 \%$ & $84 \%$ \\
\hline
\end{tabular}

\section{Comparison of analysis}

A number of the data patterns are already used by evaluators monitoring the environment. The models are divided into two parts: 1) direct observation (e.g. remote sensing with ground survey) using software techniques/ programs methods (e.g. GIS, Digital processing technology via of the satellite images). The patterns each have their weaknesses and strengths and used to collect different forms of data. The methods are therefore likely to be more appropriate at different phases in the evaluation and monitoring process of the changes. To better understand patterns for each method an effectiveness analysis was conducted based on six or more criteria: a) Temperature; b) Salinity; c) Rivers; d) Desertification; e) Groundwater; and f) Pollution. Additionally, Technical Assessment- Analysis. The weaknesses and strengths of each factor were then examined, and the results used to make recommendations on when each factor may be most appropriately applied.

\section{Conclusion}

The paper presents a list of analytical statistics evaluating the principles of remote sensing. Their shifts at the regional level, add to categorising the study of the stated objective. In solidarity, with the existence of highresolution data from local data covering the assessment rates of existing environmental change. Also, areas of distinct activity were included for use in monitoring and evaluating changes in the Iraqi environment during the period 2010-2015. It is evident from the results that remote sensing is one of the most appropriate methods to use to evaluate the performance of environmental and climatic disaster reduction in Iraq, such as providing detailed analysis and assessment of the environmental values affected by human activities in changes in the degraded landscape nature also, to help other sectors, which are related to the impact of these developments in the region. Eco-environmental priorities must be developed based on an evolving technical basis, such as for environmental evaluation and analysed the spatiotemporal variation from 2010-2015. Additionally, adopting the quality requirement of the image resolution within the sensor limits of $1.0 \mathrm{~m}$. So, to complete the holistic theory of research in providing a normative and reliable assessment of the quality of analytical work to study the disaster before and after even occurrence. Satellite imagery is available to all and has been shown to be cost-effective. A specific timetable was for analysis was set up at the beginning of practical research. In particular, once the initial mapping was finalised and the database constructed, the time and resources necessary to update and query the signature of the data set was reduced. This work, therefore, provides a scientific explanation on the preservation of data used later, before the disaster that is ideally updated every 1-5 years. Make a copy of the maps with the imagery to assess the impact of the damage, during environmental change monitoring. Overall, to show the superiority of methods and patterns of sensor techniques with GIS to the incidence of the environmental changes. High capabilities and skill focused on a highly efficient assessment of the changes that have been taking place in Iraq for a decade. To activate a comprehensive management system to reduce the damage that causes the deterioration of vital areas of human life.

\section{References}

1. A. WN, Brown K, Fairbass J, Jordan A, Paavola J, Rosendo S. A 35, 1095 (2003).

2. A. D.J. Complex Urban Systems and Extreme Events: towards a theory of disaster recovery (IC Urban Disaster Reduction, 2004).

3. Å. Nilsson, M. Brewin, C. T. Bakwatsa. Monitoring and evaluation system for the environment and natural resources sector in rwanda ( $\mathrm{Sw} 2013$ ).

4. Al-Timimi, Y. K., Monim H. Al-Jiboori. Int J E. E. 4.2, 291 (2013).

5. A. Williams, Options for results monitoring and evaluation for resilience-building operations 2016).

6. B. Indicators for disaster risk and risk management 2011).

7. B. D. Saito, K., Spence, R., Chenvidyakarn, T., Adams, B., Mcmillan, A. and Platt, S. 6th, I. RSDA. 11-12 (2008).

8. C. R., Sîrodoev, I., Koeppel, S., Denisov, N., \& Sîrodoev, G. S.W. J. 10.1155 (2013). 
9. $\mathrm{Cu}$. Disaster recovery monitoring and evaluation: centre for risk in the Built environment 2010).

10. D. S. I. P. 52.4, 444 (2015).

11. M. Agha, O.M.A., Şarlak, N. IOSR J. A. Ph, 6, 25 (2016).

12. O. M. A. Mahmood Agha, Nermin. Şarlak . Int. J. Adv. 5, 473 (2017).

13. W. D., Svoboda, M., \& Hayes, M. Monitoring drought in the United States (Ed 2005).

14. W. R. M., Fazey, I., Stafford Smith, M., Park, S. E., Eakin, H. C., Archer Van Garderen, E. R. M., \& Campbell, B. Reconceptualising adaptation to climate change as part of pathways of change and response (GECh 2014).

15. G. H. K., M. Alexander, P. Matczak, M. Pettersson, S. Bruzzone. E. So. 21, 27 (2016).

16. G. M. Borsuk, and R. B. Howarth. E. So. 22, 39 (2016).

17. UNC. (Rio de Janerio-Brazil 1992). 